\title{
A temática indígena sob as lentes dos Estudos Culturais e Educação - algumas tendências e enfoques analíticos
}

\author{
Indigenous thematic under the lens of Cultural Studies and \\ Education - some trends and analytical approaches
}

\author{
La cuestión indígena a través de la lente de los Estudios Culturales \\ y la Educación - algunas tendencias y enfoques analíticos
}

\author{
IARA TATIANA BONIN* \\ DANIELA RIPOLL** \\ JosÉ VICENTE AGUIAR***
}

\begin{abstract}
RESUMO - O objetivo deste artigo é mapear e discutir algumas tendências e enfoques analíticos que vêm sendo conduzidos em teses e dissertações do campo da Educação que se valem dos Estudos Culturais para a abordagem da temática indígena. Foram analisados 14 trabalhos que articulam três descritores: temática indígena, Estudos Culturais e Educação. Verificou-se que, em tais produções, problematiza-se a ideia abstrata de diversidade cultural, tão mobilizada pelas perspectivas multiculturalistas. Além disso, constatou-se que o campo dos Estudos Culturais favorece o desenvolvimento de análises críticas que focalizam as desigualdades, as relações de poder, as práticas representacionais e as políticas em torno das identidades/diferenças. São acionados, nestes estudos, diversos conceitos e abordagens teóricas que problematizam visões eurocêntricas, repertórios depreciativos e essencialismos, mostrando que há uma tendência hegemônica de atribuir ao "outro"/indígena características que fazem dele um ser estranho, objeto de curiosidade e de escrutínio.
\end{abstract}

Palavras-chave - Temática indígena. Estudos Culturais. Educação.

\begin{abstract}
The purpose of this article is to map and discuss some trends and analytical approaches that have been conducted in theses and dissertations of the field of education that approaches indigenous thematic through Cultural Studies. We analyzed 14 studies involving three key words: indigenous thematic, Cultural Studies and education. It was found that such productions discuss the abstract idea of cultural diversity. In addition, it was noted that the field of Cultural Studies promotes the development of critical analysis that focus on inequalities, power relations, representational practices and policies around identity/difference. In these studies, several concepts and theoretical approaches that problematize ethnocentric visions are used, showing that there is a hegemonic tendency to assign to "other"/indigenous some features that make it strange, object of curiosity and scrutiny.
\end{abstract}

Keywords - Indigenous thematic. Cultural Studies. Education.

RESUMEN - El propósito de este artículo es discutir algunas tendencias y enfoques analíticos que vienen realizándose en tesis y disertaciones del ámbito de la educación, en las que se recurre a los Estudios Culturales para abordar la cuestión indígena. Se analizaron 14 estudios que articulan tres descriptores: cuestión indígena, Estudios Culturales y educación. Pudo verificarse que, en dichas producciones, se cuestiona la idea abstracta de diversidad cultural, tan movilizada por las perspectivas multiculturalistas. Además, se constató que el ámbito de los Estudios Culturales favorece el desarrollo de análisis críticos centrados en la desigualdad, las relaciones de poder, las prácticas de representación y las políticas en torno a las identidades/diferencias. En estos estudios se activan varios conceptos y enfoques teóricos que cuestionan las visiones eurocéntricas, los repertorios despectivos y los esencialismos, mostrando que existe una tendencia hegemónica a atribuir al "otro"/indígena determinados rasgos que lo convierten en un ser extraño, un objeto de curiosidad y escrutinio.

Palabras clave - Cuestión indígena. Estudios Culturales. Educación.

\footnotetext{
* Doutora em Educação pela Universidade Federal do Rio Grande do Sul (Porto Alegre, RS, Brasil) e professora na Universidade Luterana do Brasil (Canoas, RS, Brasil).E-mail: <iara.bonin@uol.com.br>.

** Doutora em Educação pela Universidade Federal do Rio Grande do Sul (Porto Alegre, RS, Brasil) e professora na Universidade Luterana do Brasil (Canoas, RS, Brasil). E-mail: < daniela ripoll@terra.com.br>.

*** Doutor em Educação pela Universidade Federal do Rio Grande do Sul (Porto Alegre, RS, Brasil) e professor na Universidade do Estado do Amazonas
} (Manaus, AM, Brasil).E-mail: <jvicente@uea.edu.br>. 
Muito se tem escrito sobre a temática indígena no Brasil, a começar pelos textos de naturalistas e missionários nos primeiros séculos da colonização destas terras, passando pelo vasto campo da etnologia indígena, por escritos de sociólogos e de linguistas dedicados ao entendimento e catalogação das mais de 180 línguas indígenas faladas no país. No campo da educação, especialmente nas últimas décadas, esta questão se delineou com contornos específicos, na esteira das lutas pelo direito à escola e das candentes reflexões sobre identidades, diferenças e diversidade cultural. Se, em termos estatísticos, a população indígena brasileira é pouco representativa (já que corresponde a não mais que $0,6 \%$ do total de brasileiros), em termos socioculturais ela é espantosamente diversa - são mais de 340 povos indígenas diferentes, vivendo em contextos que vão desde o total isolamento em relação à cultura ocidental, até um tipo de inserção cotidiana em grandes centros urbanos.

Pode-se dizer que, a partir de 1988, o texto constitucional incorporou uma importante mudança de ênfase nas relações do Estado brasileiro com os indígenas - as constituições federais anteriores, quando mencionavam os indígenas, o faziam desde uma perspectiva integracionista que previa a dissolução das diferenças como forma de produção de uma nação unificada e homogênea. Já na atual, são reconhecidas aos indígenas suas identidades étnicas, suas práticas culturais, sociais, educacionais, religiosas e também é resguardado o usufruto exclusivo sobre as terras tradicionais que estes habitam. A ruptura proporcionada pela Constituição impulsionou, por um lado, o desenvolvimento de pesquisas interessadas em conhecer e divulgar a temática indígena e torná-la parte dos assuntos que interessam à escola e à sociedade e, por outro lado, a emergência ou o fortalecimento de movimentos de luta pela oferta de uma educação escolar diferenciada, pluricultural e multilíngue aos povos indígenas. No plano legal, foram criadas diretrizes específicas para definir como e quando se deve abordar a temática indígena nas escolas brasileiras e também foram instituídos componentes curriculares obrigatórios para disciplinas específicas. Nesta linha, a mais recente normativa é a Lei $11.645 / 2008,{ }^{1}$ instituindo a obrigatoriedade do estudo da história e da cultura indígena nos estabelecimentos de ensino públicos e privados. Também por essa razão, mas não unicamente por ela, podemos observar uma profusão de imagens, textos jornalísticos, obras de literatura, filmes, sites, blogs, materiais didáticos etc., que vão constituindo representações e discursos sobre os (e dos) indígenas, e alguns destes artefatos são objeto de estudo em pesquisas acadêmicas das últimas décadas.

O interesse acadêmico sobre tal temática, no campo da Educação, é notório quando se se realiza uma busca no banco de teses e dissertações da CAPES. Observase um expressivo número de produções decorrentes de pesquisas realizadas junto aos mais distintos povos que vivem no território brasileiro. Há, também, um volume expressivo de pesquisas acadêmicas divulgadas em periódicos referenciados do campo, focalizando processos pedagógicos, aspectos linguísticos, modelos de escola ou, ainda, realizando abordagens mais generalistas, tematizando movimentos de professores indígenas, políticas públicas destinadas a estas populações, entre outros temas.

O solo teórico a partir do qual se desenvolvem tais estudos é variado e abrangente, destacando-se, em termos quantitativos, as abordagens de inspiração póscolonial, a partir das quais se têm buscado dar visibilidade e centralidade às vozes indígenas, como também às reivindicações relativas à oferta de educação diferenciada, iniciativas de organização escolar, levando em conta as pedagogias e processos próprios de aprendizagem. Há ainda outros estudos que acabam por assumir uma abordagem celebratória da diferença, o que, muitas vezes, colabora para naturalizar certos traços culturais e essencializar identidades. Há, também, nas duas últimas décadas, uma produção crescente de pesquisas que assumem a perspectiva dos Estudos Culturais, imprimindo uma marca particular às análises da temática indígena: nestes estudos, interessa particularmente o modo como os significados são produzidos e organizados, como são produzidas e negociadas as representações, analisandose essas práticas do ponto de vista de seu envolvimento com e no interior de relações de poder.

Considerando a imensa gama de pesquisas realizadas no campo da Educação focalizando a temática indígena, e reconhecendo a impossibilidade de traçar um panorama geral sem incorrer em simplificações na abordagem destes estudos, o que se propõe, como objetivo para este artigo, é mapear e discutir algumas tendências e enfoques analíticos que vêm sendo conduzidos em teses e dissertações do campo da Educação que se valem dos Estudos Culturais para a abordagem da temática indígena.

Como primeiro passo para proceder à seleção dos trabalhos que seriam incorporados, foram consultados os Anais das quatro edições do Seminário Brasileiro de Estudos Culturais e Educação, evento promovido pelo Programa de Pós-Graduação em Educação da ULBRA desde 2004. Tal procedimento possibilitou identificar três importantes núcleos de estudos nos quais a temática indígena tem sido dinamizada e discutida em três Programas de Pós-Graduação em Educação, com aportes dos Estudos Culturais: a) Universidade Federal do Rio Grande do Sul, que possui uma linha de pesquisa em Estudos Culturais e Educação; b) Universidade Luterana do Brasil, cujo curso de Mestrado em Educação possui 
área de concentração em Estudos Culturais; c) e a Universidade Católica Dom Bosco, que possui uma linha de pesquisa dedicada ao tema da diversidade cultural e educação indígena, na qual também se desenvolvem investigações respaldadas teoricamente no campo dos Estudos Culturais. Além dos Programas já referidos, encontramos uma grande variedade de trabalhos que indicam a articulação entre a temática indígena e a Educação, valendo-se também de aportes teóricos do campo dos Estudos Culturais (embora não se explicite tal vinculação em resumos, palavras-chave e sumário das pesquisas). Tais produções concentram-se, em especial, nos Programas de Pós-Graduação em Educação da Universidade Federal de Minas Gerais e da Pontifícia Universidade Católica de São Paulo. Por considerarmos amplo demais o recorte no qual se pudessem contemplar todos estes estudos, e nos limites estabelecidos para este artigo, preferimos nos ater aos três programas anteriormente referidos, por encontrarmos neles linhas de pesquisa específicas, nas quais se declara o pertencimento das pesquisas ao campo teórico que aqui nos interessa - o dos Estudos Culturais pós-estruturalistas. O rastreamento e a análise de um conjunto mais amplo de instituições nos parece uma tarefa estimulante, que será realizada no devido tempo, em publicações futuras.

Realizamos, então, uma consulta às bibliotecas virtuais de dissertações e teses das três instituições (LUME-UFRGS, ${ }^{2}$ banco de dissertações defendidas/ $\mathrm{ULBRA}^{3}$ e banco de dissertações defendidas/ $\mathrm{UCDB}^{4}$ ) e, nesta etapa, foram selecionadas as pesquisas realizadas entre 2000 e 2012, nas quais a tríade "temática indígena", "Educação" e "Estudos Culturais" estivesse claramente evidenciada, resultando em 14 produções, que serão a seguir apresentadas.

\section{BREVE CARACTERIZAÇÃO DOS ESTUDOS E DOS FOCOS DE DISCUSSÃO}

Considerando as pesquisas no seu conjunto, observase que 10 delas têm na temática indígena o seu foco principal, examinando então as representações em artefatos midiáticos, em documentos históricos ou, ainda, são caracterizados como estudos realizados in loco, envolvendo comunidades indígenas de diferentes etnias. Outras quatro pesquisas focalizam representações de natureza, da Amazônia, ou a produção de marcas culturais de gênero, etnia, nação e, nestes estudos, a problemática da diferença indígena é também abordada em seções ou capítulos específicos no texto.

Entre os estudos cujo problema de pesquisa vinculase diretamente à temática indígena, a dissertação de mestrado de Teresinha Oliveira $(2001)^{5}$ é uma das mais antigas, e objetivou discutir as representações de índio que se expressam, de modo especial, nos livros didáticos de ciências e em outras produções midiáticas impressas. A autora seleciona, para compor o corpus da pesquisa, oito livros didáticos de ciências e 10 reportagens de revistas e jornais de grande circulação.

$\mathrm{Na}$ mesma direção, a tese de doutorado de Iara Bonin $(2007)^{6}$ problematiza discursos sobre povos indígenas que se constituem em diferentes espaços e artefatos culturais, e que são acionados nas narrativas de estudantes do ensino superior, quando estes se manifestam sobre a temática indígena. A autora focaliza algumas práticas de significação que constituem e posicionam os povos indígenas na diferença, processo implicado com relações de poder/saber. A pesquisa empírica envolveu 68 estudantes de licenciatura, vinculados a duas universidades da região metropolitana de Porto Alegre. Foram organizados quatro grupos e, em cada um deles, ocorreram quatro encontros (inspirados em técnicas de Grupos Focais) para a produção das narrativas examinadas na pesquisa. Além das narrativas orais, foram analisados também os textos escritos e/ou desenhos produzidos, além de outros materiais trazidos para os encontros pelos participantes. Valendose dos conceitos de cultura, linguagem, discurso, identidade/diferença, a autora analisa as formas como são narrados os povos indígenas, discorre sobre algumas fontes de informação e alguns saberes referenciais que colaboram para posicionar, nomear, descrever e caracterizar os povos indígenas nas narrativas dos estudantes e argumenta que a retórica sobre os "outros", os indígenas, colabora para a constituição de subjetividades, incluindo aqueles que narram e não somente os que são narrados.

Problematizando também as representações de povos indígenas em espaços escolares, a dissertação de mestrado de Valéria Calderoni (2011) 7 investiga as representações da identidade e diferença indígena nos dizeres de docentes de uma escola pública da educação básica. Inicialmente, a autora aplicou um questionário com quarenta e seis docentes dessa escola. Desse universo, selecionou seis docentes para realizar com eles uma pesquisa qualitativa, a partir de entrevistas semiestruturadas. Embora o foco da pesquisa não fosse a escola e, sim, os dizeres dos docentes sobre os alunos índios, a autora descreve algumas cenas do contexto escolar, relacionando-as com os eixos de análise. Destaca-se o conceito de diferença como central para a análise das formas como se naturalizam e harmonizam as relações interétnicas conflituosas, sob o argumento da igualdade, uma metanarrativa da modernidade.

Valendo-se do conceito de pedagogias culturais, a partir do qual se admite que a aprendizagem não ocorre apenas em espaços formais e, sim, se processa cotidianamente em uma variedade de instâncias e âmbitos da cultura, a tese de doutorado de Maria Helena Paes 
$(2008)^{8}$ realiza uma análise sobre as narrativas fílmicas brasileiras, produzidas a partir de 1970, nas quais se inserem personagens indígenas (Como era gostoso o meu francês, Avaetê, Semente da vingança, O Guarani, Hans Standen, Caramuru, A invenção do Brasil, Tainá: uma aventura na Amazônia e Tainá 2: a aventura continua). A autora recorreu a teorizações pós-estruturalistas, dinamizando suas análises com conceitos como discurso, poder e verdade, numa abordagem foucaultiana, realizando aproximações destes com teorizações de Michel Hardt e Antonio Negri, Stuart Hall, Fredric Jameson, François Lyotard e Zygmunt Bauman. Seu foco são dispositivos discursivos que visam capturar os sujeitos e que os conclamam para a valorização das diferenças culturais na atualidade.

A tese de doutorado de José Vicente de Souza Aguiar $(2012)^{9}$ focalizou a emergência de certos discursos sobre os povos indígenas na Amazônia entre a segunda metade do século XVIII e a primeira do século XX, com o objetivo de localizar uma rede narrativa que potencialmente participa na constituição dos tipos sociais chamados de "indígenas". Para isso, o autor realizou o rastreamento e a análise de algumas narrativas produzidas por sujeitos que, em diferentes contextos históricos, dispunham de um respaldo religioso ou acadêmico, para definir como eram e deveriam ser os povos indígenas.

Em termos metodológicos, Aguiar (2012) analisa dois conjuntos de textos, correspondentes a dois momentos significativos na produção narrativas sobre as etnias amazônicas. Um primeiro conjunto é constituído de obras escritas por jesuítas do século XVIII, com destaque para as dos padres João Daniel, Cristóbal de Acuña e Samuel Fritz. Esses religiosos atuaram na Amazônia, buscando promover mudanças nos comportamentos dos indígenas, de forma a incorporá-los ao processo de expansão do cristianismo e da produção agrícola, por exemplo. Um segundo conjunto de textos corresponde ao que foi produzido por viajantes-cientistas-naturalistas do século XIX, e também por documentos redigidos por representantes das instituições de Estado e informações divulgadas em periódicos diários e semanais a respeito dos povos indígenas da Amazônia.

$\mathrm{Na}$ esteira de teorizações que buscam produzir um alargamento do campo pedagógico, a dissertação de Kassius Nitske da Silva $(2012)^{10}$ dedica-se à análise dos Jogos dos Povos Indígenas, um evento contemporâneo no qual se entrelaçam práticas provenientes de culturas e tradições diversas e no qual se constituem múltiplas representações sobre os povos indígenas. Interessam principalmente ao autor as estratégias pedagógicas colocadas em ação nos Jogos dos Povos Indígenas para ensinar sobre o "ser índio", seu lugar, suas características e formas de expressão na atualidade. No estudo, ele se vale particularmente dos conceitos de representação e de identidade, componentes do chamado circuito da cultura, bem como do conceito de hibridação, a partir das teorizações de autores como Néstor Garcia Canclini e Jésus Martin Barbero. A metodologia consistiu na realização de observações de inspiração etnográfica na XI edição dos Jogos dos Povos Indígenas, ocorrida em Porto Nacional/TO no ano de 2011, bem como no registro de conversas informais com atletas, organizadores e participantes dessa edição dos Jogos, registradas em um diário de campo. Na pesquisa, também foram levadas em conta fotografias e reportagens publicadas em sites oficiais do Governo Federal divulgando o evento.

Em alguns dos trabalhos aqui discutidos, os pesquisadores realizam imersões ao cotidiano da vida indígena, desenvolvendo pesquisas etnográficas que focalizam temas concernentes ao campo da educação. É o caso da dissertação de Mestrado de Luís Antônio Catafesto de Souza (2010), ${ }^{11}$ que analisa algumas práticas educativas dos Mbyá-Guarani, em especial os processos de nomeação, as noções de mobilidade espacial, de temporalidade e as diferenciações etárias como parte das tecnologias de produção da pessoa. $\mathrm{O}$ autor realizou visitas a sete aldeias Mbyá-Guarani localizadas no estado do Rio Grande do Sul, entre 2008 e 2009. Para desenvolver suas análises, fez uso de um conjunto de estudos antropológicos clássicos e um conjunto de textos acadêmicos contemporâneos, dedicados ao estudo dos Mbyá-Guarani.

Já a dissertação de mestrado de Teresinha Aparecida da Silva Batista (2005) ${ }^{12}$ discorre sobre as práticas e processos de mudança da escola Kaiowá e Guarani, localizada em Te'yikue, município de Caarapó, Mato Grosso do Sul. A pesquisa está pautada na experiência da educação municipal implantada a partir de 1997 e destaca a importância da Comissão dos Professores Indígenas e de um projeto de Magistério Específico, voltado à formação de professores indígenas. O trabalho vem apoiado nos Estudos Culturais e em experiências em educação escolar indígena, bem como na análise de relatórios, documentos e depoimentos dos professores e lideranças indígenas.

A dissertação de mestrado de Rogério Batalha Rocha Moroni (2012) $)^{13}$ teve por objetivo investigar os parâmetros das escolas situadas nas terras indígenas Kaiowá e Guarani, em Mato Grosso do Sul, para a efetividade dos direitos indígenas e as percepções/concepções de professores sobre sustentabilidade e territorialidade. A metodologia da pesquisa ficou concentrada em pressupostos qualitativos, incluindo entrevistas com professores indígenas, a participação em etapas de curso de formação de professores e na revisão de textos legais e normativos vigentes no Estado brasileiro. Para discutir aspectos do cotidiano escolar, currículo e interculturalidade, ele 
recorre a escritos de Vera Candau, Carlos Skliar, Cary Nelson, Catherine Walsh, Lawrence Grossberg, Jorge Larrosa, Núria Pérez de Lara Ferre, Stuart Hall, Zygmunt Bauman, entre outros. Sobre educação, sustentabilidade e processos de territorialização Kaiowá e Guarani, o autor se vale de estudos de Aguilera Urquiza, Antonio Brand e Adir Casaro Nascimento.

Destaca-se, a seguir, outro conjunto de pesquisas de mestrado e doutorado que, mesmo focalizando outras temáticas, dedicam-se à problematização de representações dos povos indígenas em seções ou capítulos de seus trabalhos. Esse é o caso da tese de Eunice Kindel (2003),${ }^{14}$ na qual a autora analisa os filmes de animação (produzidos pelos estúdios Disney e Dreamworks na década de 1990), Vida de Inseto, O Rei Leão, O Rei Leão II, FormiguinhaZ, Pocahontas e Tarzan. Tais filmes são considerados pedagógicos e o objetivo da pesquisa é, então, mostrar como tais produções constituem e fazem circular representações culturais de natureza articuladas a outras representações. Para isso, a autora opera com os conceitos de cultura, representação, identidade e diferença (de gênero, sexual, racial, nacional, étnica e de classe).

Já a tese de Doutorado de Marise Basso Amaral (2003) $)^{15}$ examina os relatos de viagem feitos por Auguste de Saint-Hilaire, Arsène Isabelle, Nicolaus Dreys e Aimé Bonpland, quatro viajantes-naturalistas franceses que estiveram no Rio Grande do Sul na primeira metade do século XIX. Seu objetivo é mostrar como, ao narrar a natureza, tais naturalistas também a constituíam e a configuravam como "selvagem", "bela", "inóspita", "exótica", "sublime", "primitiva" e "pitoresca", bem como imprimiam à paisagem (e aos povos que aqui viviam) um olhar higienista, colonizador, europeu, branco. O objeto de interesse de Amaral são as representações eurocêntricas de natureza produzidas pelos/nos diários de viagem dos naturalistas, mas outras representações - em especial, aquelas relacionadas aos "outros" que aqui estavam - também foram surgindo ao longo da investigação. Em termos metodológicos, a autora vincula-se às discussões empreendidas pelos Estudos Culturais de Ciência, e se vale de autores e obras das áreas da História Cultural, da História Natural Crítica, da Literatura de Viagem e da Teoria Literária. Ela utiliza a noção de "texto" - e, mais especificamente, de "viagem enquanto texto" - para, então, proceder a uma análise que é tanto textual quanto cultural e discursiva.

Gilcilene Dias da Costa $(2003)^{16}$ se propõe a discutir modos de ver e narrar as diferenças na Revista Nova Escola. Valendo-se da noção de pedagogias culturais, a autora considera a revista como um influente instrumento pedagógico que vem contribuindo para a constituição de identidades e diferenças. A autora seleciona para análise matérias, imagens, reportagens, entrevistas e depoimentos publicados na revista Nova Escola, entre 1997 e 2001, que focalizam diferenças. Relativamente à temática indígena, a autora discute as reportagens "Viva a diferença!", "O índio redescoberto!" e "O silêncio vai acabar!", e aborda, entre outros aspectos, a "referência identitária" a partir da qual os indígenas são narrados e as formas como estes povos têm sido nomeados, produzidos e veiculados na revista.

A Tese de Shaula Sampaio (2012) ${ }^{17}$ discute a produção de significados sobre a Floresta Amazônica e sobre as populações tradicionais na mídia brasileira. A autora analisa reportagens publicadas nas versões online de jornais brasileiros de grande circulação (Folha de S. Paulo, O Estado de São Paulo, Valor Econômico e $O$ Globo) entre os anos de 2007 e 2011 para, assim, problematizar a premissa de que as populações ditas tradicionais apresentam modos de habitar a floresta e de se relacionar com a natureza considerados mais adequados e sustentáveis. A autora vale-se dos conceitos de "articulação" (Hall; Slack), "modos de endereçamento" (Ellsworth), "governamento", "dispositivo" e "discurso" (Foucault). A autora também utiliza a noção de "estatuto pedagógico da mídia" (Fischer).

Por fim, a dissertação de Moema Gudes Urquiza $(2013)^{18}$ analisa as representações e identidades indígenas forjadas no/pelo discursos midiático, bem como as formas como essas mensagens veiculadas em diferentes artefatos são percebidas por professores indígenas de etnias que vivem em Mato Grosso do Sul. Os procedimentos teórico-metodológicos envolveram a seleção de notícias veiculadas em meios eletrônicos e impressos, aplicação de questionário objetivo com professores indígenas e seleção de seis destes para a realização de entrevistas semiestruturadas. Os conceitos de identidade/diferença e representação foram acionados a partir de teorizações culturalistas, em especial em textos de Stuart Hall, Homi Bhabha e Tomaz Tadeu da Silva. A autora também considerou argumentações relativas à alteridade, tomando por base textos de Carlos Skliar e Jorge Larrosa. Após discutir como, em variadas notícias, reportagens e imagens, os indígenas vão sendo apresentados e posicionados pela mídia, a autora coloca em diálogo alguns textos teóricos e falas dos professores indígenas, para apresentar um quadro no qual se constituem identidades indígenas mediadas por aparatos midiáticos.

Tendo realizado uma breve apresentação das pesquisas de mestrado e doutorado selecionadas para compor o corpus deste artigo, apresentam-se e discutem-se, a partir daqui, algumas decorrências, para a pesquisa acadêmica, da articulação entre temática indígena, Educação e Estudos Culturais. Consideram-se, em especial, as escolhas teórico-metodológicas empreendidas pelos pesquisadores e alguns achados destes estudos como sendo indicadores da produtividade de tal articulação. 


\section{A TEMÁTICA INDÍGENA SOB AS LENTES DOS ESTUDOS Culturais E EduCAÇÃo - Algumas POSSIBILIDADES ANALÍTICAS}

Nesta seção discutem-se alguns dos resultados apresentados nas pesquisas sobre a temática indígena que se vinculam ao campo dos Estudos Culturais. Inicialmente, vale ressaltar que as pesquisas partem de uma variedade de estratégias metodológicas (etnografia, análise cultural em relatos de viagem, em jornais, revistas, livros didáticos, fotografias, análise de narrativas, entrevistas, questionários etc.) e um amplo leque conceitual (apresentado adiante), o que conduz a análises variadas, abrangentes, complexas, sutis, críticas, desconstrutivas. Pode-se dizer que tamanha variedade é resultante da proposição, no campo dos Estudos Culturais, de que os caminhos investigativos podem e devem ser construídos no processo de pesquisar, não existindo uma metodologia boa ou adequada a priori.

Prosseguindo com a análise de algumas decorrências e resultados da articulação entre temática indígena, Educação e Estudos Culturais, examinam-se agora alguns "achados" das pesquisas. Ressalta-se, contudo, que a intenção não é dar conta da infinidade de conclusões (ainda que provisórias) indicadas nestes textos. O intuito, bem mais modesto, é o de indicar alguns direcionamentos analíticos comuns, organizados a partir da recorrência de dois conceitos principais - o de representação e o de identidade/diferença.

\section{a) Políticas representacionais em foco}

$\mathrm{O}$ primeiro aspecto que adquire visibilidade quando se examina articuladamente as 14 teses e dissertações selecionadas diz respeito à centralidade que assume a análise das políticas representacionais. Representação parece ser um conceito aglutinador, e está presente em quase todos os estudos, acionado por um viés construcionista. Assim, os autores preocupam-se em discutir como são nomeados, descritos, caracterizados os indígenas, entendendo que as representações não revelam a ontologia do "ser índio" e, sim, a fabricam. Em estudos de viés culturalista existe uma ênfase sobre a produção de significados nos diferentes momentos e práticas que integram o circuito da cultura (ou seja, na produção, no consumo, na representação, na construção de identidades/diferenças, na regulação das condutas sociais). Conforme Hall (1997), os significados não são nunca fixados, e seguem sempre diferindo, o que impede qualquer redução simplista do significado à representação. Embora o conceito seja tomado, nestes estudos, a partir de um direcionamento teórico comum, os modos como cada autor opera com ele são variáveis.
Aguiar (2012), por exemplo, discorre sobre os processos de nomeação, classificação, hierarquização e caracterização dos indígenas em narrativas de mais de um século, destacando uma matriz a partir da qual se constitui o "tipo social indígena", cujos traços são facilmente reconhecidos e reiterados em diferentes produções culturais. Também Amaral (2003) recorre a narrativas de viajantes do século XIX, indagando sobre as formas como, ao narrar a floresta, tais relatos configuram também representações de indígenas, habitantes deste universo natural. Há pesquisas que ocupam das representações de índio em produções fílmicas (KINDEL, 2003; PAES, 2008), em fontes virtuais e em fotografias (SILVA, 2012), revistas (COSTA, 2003) e jornais brasileiros de grande circulação (SAMPAIO, 2012).

Outra fonte de dados utilizada em algumas pesquisas é a narrativa oral, e os autores discorrem sobre o modo como variadas informações, imagens e mensagens convergem na produção de representações sobre indígenas, e vem compor os repertórios argumentativos dos sujeitos envolvidos. É o caso da pesquisa de Bonin (2007), que examina representações constituídas por estudantes do ensino superior; Calderoni (2011), que realizou entrevistas com professores da educação básica; Souza (2010), que realizou uma etnografia em aldeias Mbyá-Guarani e reuniu depoimentos indígenas; Moroni (2012) e Urquiza (2013), que entrevistaram estudantes indígenas que cursam o ensino superior. Vale indicar que a opção por dialogar com professores indígenas sobre as representações midiáticas, feita por Urquiza, oportunizou tomá-los como interlocutores privilegiados na pesquisa, incluindo assim falas de sujeitos fracamente conformadas em/com representações mais usuais do que seja a vida indígena, por estarem sendo produzidas em outros lugares culturais (próprios das etnias às quais pertencem estes professores).

$\mathrm{O}$ cotejo entre as variadas pesquisas possibilita observar o uso de uma estratégia analítica comum, qual seja, o rastreamento de um repertório (ou de uma terminologia) a partir do qual são apresentados e descritos os povos indígenas. A atenção às palavras utilizadas para nomear, caracterizar, explicar, posicionar os indígenas dá conta da premissa do campo dos Estudos Culturais de que a linguagem não é um meio transparente, não apenas relata e, sim, constitui os fatos, objetos, sujeitos de que se fala. Nesta direção, Aguiar (2012) discute vocábulos utilizados na composição das narrativas de jesuítas e de naturalistas do século XIX, que conformam e posicionam os indígenas em certos lugares sociais. Ele examina as circunstâncias a partir das quais os termos selvagens, civilizados, mansos, preguiçosos, rudes, indolentes, hereges, feiticeiros foram utilizados na historiografia e as decorrências dessas adjetivações. $\mathrm{Na}$ mesma 
linha, Amaral (2003) afirma que a literatura de viagem (que ela examina em sua tese) auxiliou na construção daquilo que passou a ser entendido como "próprio" e "típico" dos índios brasileiros. Ela rastreia expressões a partir das quais os índios foram sendo descritos pelos viajantes, que caracterizam e marcam supostos atributos, como, por exemplo, a infantilidade, a brandura e fácil subserviência; a docilidade natural, a inclinação natural para o trabalho agrícola, o amor à vida solitária. Vale lembrar que, especialmente em meio à industrialização da Europa e a diversos tipos de colonialismo, um discurso de base racista se desenvolveu assentado sobre um conjunto de doutrinas e teorias científicas, a partir do qual as culturas não ocidentais foram consideradas inferiores e deficitárias, não apenas por seus caracteres externos como cor da pele, largura do crânio, textura capilar etc., como também em relação à capacidade de raciocínio, sendo a colonização entendida inclusive como uma forma de intervenção civilizatória. A literatura e os relatos científicos (examinados nas pesquisas anteriormente referidas) foram pródigos na disseminação de asserções depreciativas relativamente às populações indígenas.

Oliveira (2001), Costa (2003) e Bonin (2007) afirmam que muitas produções didáticas, literárias, imagéticas de nosso tempo ainda se valem de certa retórica depreciativa - elas sinalizam, por exemplo, para a manutenção de palavras como tribo, oca, taba, morubixaba para falar de espaços e artefatos indígenas e de adjetivações como primitivos, não civilizados, rudes, cruéis, selvagens para fazer referência a estes sujeitos. Valendo-se do conceito de representação, as autoras também destacam que o desprestígio da cultura indígena se processa, talvez mais veementemente, no modo como acontecimentos históricos são narrados - invasões europeias do período colonial figuram como atos de descobrimento, massacres indígenas são tidos como feitos heroicos, enquanto lutas populares recebem qualificativos como rebeliões, insurreições, revoltas.

A estratégia retórica de narrar por estereótipos é destacada pelos pesquisadores como sendo recorrente. Oliveira (2001) afirma que alguns "traços" físicos individuais são apresentados como sendo característicos desta coletividade genérica - "os índios". Assim, as imagens da vida indígena "traduzidas" através de fotografias, gravuras, pinturas dispostas em livros didáticos assentam-se mais fortemente em generalidades e visões estereotipadas do que em especificidades culturais que diferenciariam as etnias entre si. Bonin (2007) também discute a emergência de uma noção estereotipada e genérica que informa que os índios vivem nus, portam arcos e flechas, têm pele cor de cuia, olhos amendoados, cabelos lisos e negros, vivem em ocas, adoram o sol e a lua etc. Tal estratégia impede que a pluralidade de maneiras de ser e de viver, das tantas etnias indígenas brasileiras, seja levada em conta.

A pesquisa realizada por Calderoni (2011), a partir de depoimentos de docentes da educação básica, também possibilita identificar afirmações do tipo: usam roupas estranhas, portam arcos e flechas, pintam o rosto e moram na mata. A imagem retratada é de um índio "universal", que parece migrar diretamente das representações de livros didáticos para as salas de aula, acionando significados que imobilizam, fixam e marcam a diferença indígena, tornando "invisíveis" os alunos índios que frequentam a escola, conclui a autora.

Seguindo nesta direção, o estudo de Gilcilene Costa (2003) mostra que a entrada dos indígenas em reportagens jornalísticas se dá, muito frequentemente, pela via do discurso folclórico, que produz um texto único no qual se inserem as diferenças como componentes de uma totalidade maior. A autora salienta que as narrativas sobre os indígenas estão marcadas por uma forte carga de exotismo, especialmente quando vinculadas à região amazônica. Ela localiza e discute representações, nas quais os índios figuram ora como vítimas de atrocidades, preconceitos, discriminações, ora como objetos epistemológicos a serem conhecidos na escola.

Silva (2012), ao analisar os Jogos dos Povos Indígenas como espaço de mescla e hibridação cultural, também lembra que as culturas indígenas são dinâmicas e se reconfiguram constantemente, não sendo, portanto, capturadas completamente. As formas contemporâneas de inserção dos indígenas no cotidiano urbano, em produções de autoria indígena, no uso de aparatos e recursos tecnológicos, torna problemática a busca por uma única explicação, uma verdade incontestável, uma representação conciliadora daquilo que segue sempre diferindo.

Os estudos que problematizam imagens estereotipadas permitem pensar que tal estratégia funciona reduzindo a ambivalência, a complexidade, a profusão de sentidos ao falar da diferença indígena, marcando, assim, o que conta, o que deve ser reiterado na cultura escolar. O uso recorrente de estereótipos opera certa forma de conhecimento e de identificação naturalizada e inquestionável. Pode-se dizer que as teorizações do campo dos Estudos Culturais possibilitam pensar na representação por estereótipos como engrenagem útil para tentar fixar a diferença, para marcá-la nos corpos, para estabelecer seu lugar "natural" (BONIN, 2007). Conforme salienta Hall (1997), "o estereótipo reduz, essencializa, naturaliza e estabelece a diferença” (p. 258).

Há, ainda, um terceiro aspecto, relativo ao jogo das representações, que as pesquisas acadêmicas vinculadas ao campo dos Estudos Culturais e da Educação têm enfatizado: trata-se da produção de significados com base 
numa lógica binária, a partir da qual se classificam sujeitos e práticas culturais por oposições hierarquicamente díspares. No caso das pesquisas acadêmicas selecionadas para este estudo, observa-se a problematização do par cultura/natureza. Neste sentido, Bonin (2007) ressalta que a lógica binária configura um tipo específico de ordenamento e de visibilidade (a identidade seria positiva e a diferença negativa). Assim, a articulação produzida entre índio e natureza funcionaria como uma espécie de chave de leitura, sendo os povos indígenas narrados como habitantes naturais da floresta, lugar geográfico e social que produz também um conjunto de atributos, colados ao corpo e apresentados como sendo próprios da "natureza indígena". Habitando o mundo natural, os povos indígenas teriam características como primitivismo, espontaneidade, ingenuidade. A natureza, neste binômio, é um marcador importante que entrelaça as vidas indígenas, em oposição à cultura. Amaral (2003) destaca que, na colonização do Brasil, vários textos de viajantes descrevem-no como um lugar "essencialmente tropical", com imensas florestas, frutas exóticas, animais ferozes, flores belíssimas, rios intransponíveis e caudalosos, índios apáticos, ignorantes, condenados por natureza à degeneração, sem senso de futuro, desfrutando de tamanha riqueza natural. Tal representação colabora para respaldar o empreendimento colonial como sendo uma possibilidade de redenção do primitivismo e da barbárie.

$\mathrm{Na}$ mesma direção, mas examinando filmes de animação, Kindel (2003) discute o enredo de Pocahontas e mostra como os ingleses são apresentados aos expectadores como civilizados, em oposição aos indígenas, que seriam selvagens, primitivos, mas também teriam à disposição os recursos infindáveis de uma terra grandiosa e imponente. Em determinados trechos do desenho em questão, a autora pontua a existência de outra característica utilizada para "marcar" os povos indígenas nos desenhos animados: o culto à ancestralidade. Tal culto, segundo a autora, "se associa ao respeito às ideias dos mais velhos, considerados mais sábios, enquanto conhecedores das histórias relativas às origens do povo, seus costumes, enfim, de tudo aquilo capaz de assegurar a permanência das tradições que os instituem e configuram como um povo diferenciado de outros" (p. 127). Essa característica, associada à noção de serem os índios governados pela magia, é utilizada no filme para confirmar que "o civilizado é bom" e deve ser bem acolhido, - é o espírito da avó da protagonista, Pocahontas, que confirma que ela deve render-se aos encantos do colonizador John Smith. De acordo com Calderoni (2011), no cotidiano escolar ainda são reiteradas imagens de um índio universal, cuja maneira de viver seria simples e primitiva, valendo-se do binômio pensamento complexo/pensamento simples (sendo primeiro termo atribuído ao pensar ocidental).
Nos filmes do cinema nacional, Paes (2008) identifica certo deslocamento processado nesta noção mais geral de indio selvagem, ressaltando-se então a de índio protetor da natureza em certas narrativas sobre os povos indígenas das últimas décadas. Ainda assim, pode-se dizer que opera o binômio cultura/natureza, mesmo sendo a "natureza indígena" ressignificada em produções mais recentes. As análises empreendidas por Oliveira (2001) em livros didáticos de ciências também mostram que os índios são vinculados ao mundo natural (mais que a um mundo cultural), seja pelo cenário construído para habitarem, seja por atitudes e valores a eles associados. Eles são também caracterizados como sujeitos que vivem em comunhão com a natureza e, por isso, seriam conhecedores e protetores naturais do meio ambiente. Mas a autora salienta que, em alguns casos, a aproximação à natureza também os converte discursivamente em selvagens e primitivos.

As análises discursivas levadas a efeito por Sampaio (2012) em artefatos midiáticos mostram uma série de tensões entre discursos "desenvolvimentistas" e "preservacionistas". Nesse contexto, um significado recorrente é "o pressuposto de que determinadas culturas que recebem denominações como 'locais', 'tradicionais', 'nativas' ou 'autóctones' - seriam mais puras e autênticas do que as culturas urbanas, por estarem mais intimamente ligadas à natureza" (p. 12). Desse modo, as reportagens por ela analisadas enfatizam a importância das populações ditas tradicionais para a conservação da biodiversidade, em função de seu estilo de vida puro e integrado com a natureza. Ao enfatizar as "riquezas escondidas" na floresta amazônica - vista como um "tesouro biológico" - as reportagens reiteram que as populações tradicionais seriam as melhores guardiãs da natureza (ou, no limite, suas principais exploradoras, cooptadas por multinacionais, laboratórios de pesquisa, cientistas etc.).

\section{b) Identidades/diferenças em foco}

A cultura é um dos aspectos ressaltados nas abordagens teóricas das pesquisas selecionadas para este estudo. Respaldando-se em Stuart Hall, Néstor Garcia Canclini, Homi Bhabha, George Yúdice, entre outros, alguns destes estudos reafirmam o sentido da cultura como um processo integral através do qual significados e definições são socialmente construídos e historicamente transformados, incluindo-se aí as formas de pertencimento e de identificação. Nessa direção, no conjunto de pesquisas aqui examinadas, adquire relevo o conceito de identidade/ diferença, acionado na condição de ferramenta analítica. Vale ressaltar que essas produções acadêmicas marcam textualmente o distanciamento em relação às abordagens essencialistas da identidade, bem como às vertentes da filosofia da consciência, que propõem a existência de um "eu" autônomo, reflexivo, crítico e consciente, não 
dependente da linguagem. Fazendo referência a autores como Kathryn Woodward, Stuart Hall, Tomaz Tadeu da Silva e, em alguns casos, Zygmunt Bauman, as pesquisas frisam o caráter fragmentado, fluido, cambiante das identidades, dando relevo ao fato de serem elas construídas e transformadas continuamente em políticas representacionais e em relações de poder.

A perspectiva construcionista empresta a estes estudos sobre a temática indígena um olhar atento ao dinamismo e à fragmentação, de tal modo que não passam incólumes os discursos que demarcam fronteiras fixas para as identidades étnicas, e aqueles que estabelecem "a verdade" sobre quem são e como são os sujeitos indígenas, tampouco aqueles que apregoam a pureza das culturas, buscando circunscrevê-las em traços invariáveis, "típicos", exóticos. Neste sentido, a pesquisa de Bonin (2007), por exemplo, problematiza certos regimes de verdade a partir dos quais se naturalizam características específicas como sendo generalizáveis e aplicáveis a todo e qualquer indígena. Ela também afirma que a obsessão por explicar, definir, nomear, caracterizar as identidades indígenas responde ao anseio moderno da busca da ordem - no qual cada coisa e cada sujeito ocupa um (único) lugar.

Em seu estudo, Urquiza (2013) parte da análise de algumas mensagens midiáticas que se valem de critérios eurocêntricos para, então, mostrar como ali se procede a uma classificação de quem é mais e quem é menos indígena, quando se noticia, por exemplo, lutas pela demarcação dos territórios, disputas por recursos ou políticas públicas. Estranha-se, nestes casos, sua presença das cidades (e não nas florestas), o uso de roupas, a posse de artefatos tecnológicos - estes seriam sinais da perda de uma suposta pureza.

Já Silva (2012), ao examinar os Jogos dos Povos Indígenas, mostra que neste espaço se constitui uma ampla rede de significados sobre a diferença indígena, mas, em grande medida, expectadores e responsáveis pela cobertura jornalística do evento buscam encontrar ali a "pureza" das práticas tradicionais (tais como a corrida de toras, disputas de arco e flecha, entre outras). Não é raro que os olhares (e os flashes de câmeras fotográficas) se voltem para as etnias mais bem paramentadas, ou seja, as que correspondem mais precisamente ao estereótipo do que seja "um índio".

O campo dos Estudos Culturais tem possibilitado aos pesquisadores escapar à armadilha de tentar encontrar uma identidade unificada, coesa, verdadeira, o que permite a explicitação de uma multiplicidade de maneiras de ser e de pertencer a uma dada etnia indígena. $O$ uso do conceito de hibridação (cunhado por Néstor Garcia Canclini) para pensar as identidades e práticas culturais indígenas tem se mostrado produtivo para operar o deslocamento de abordagens essencialistas. Na pesquisa de mestrado de
Silva (2012), examinam-se, por exemplo, as modalidades esportivas de uma das edições dos Jogos dos Povos Indígenas, bem como as negociações que antecedem o evento e alguns depoimentos indígenas. $\mathrm{O}$ autor argumenta que os jogos são uma contundente manifestação de que as culturas são dinâmicas e se reconfiguram continuamente, mesclando elementos de diferentes proveniências. E ele mostra que não apenas as práticas corporais desenvolvidas neste evento compõem-se na mescla de elementos de muitas tradições indígenas e da tradição olímpica, como também os corpos mesclam componentes de diferentes "mundos": pinturas características de uma etnia mescladas a adornos e cocares comprados de (ou permutados com) indígenas de outras localidades, roupas coloridas, por vezes customizadas, tênis de certa grife, câmeras, aparelhos celulares, máquinas fotográficas etc. Para o autor, a análise dos processos de hibridação é útil para desacomodar noções naturalizadas sobre indígenas vivendo em meio à natureza, distantes das práticas da sociedade ocidental contemporânea.

Também Urquiza (2013) mostra a pluralidade e a fragmentação das identidades indígenas a partir das narrativas de textos midiáticos dos quais se vale para seu estudo. De acordo com a autora, eles figuram como vilões e protagonistas de tragédias urbanas (por exemplo, as notícias de tráfico de drogas em aldeias e da superpopulação em certas comunidades, o que intensifica a violência entre os indígenas); aparecem como sujeitos vulneráveis, vítimas de agressões e da omissão do poder público (notícias sobre desnutrição, assassinatos, suicídios, invasão das terras, discriminação, entre outras); emergem, também, como empreendedores, inovadores, sujeitos criativos, conectados com novos tempos (é o caso das reportagens sobre o Rap do Brô, criado nas aldeias de Dourados, convidados a apresentar-se inclusive no programa Show da Xuxa); e, por fim, emergem como sujeitos políticos, quando realizam mobilizações, atos, protestos, a partir dos quais se pautam notícias, divulgam-se depoimentos, entrevistas e outras formas de expressão indígenas.

Outra direção interessante seguida por alguns pesquisadores é a discussão e análise de práticas culturais específicas de uma dada etnia, sob um viés que considera a cultura como processo dinâmico e central. Exemplo deste tipo de abordagem é o estudo de Catafesto de Souza (2010) que se dedica à análise de processos implicados na produção da pessoa Mbyá Guarani. Focalizando as subjetividades como construtos culturais, ele põe em relevo uma rede de ações, de sujeitos, de espaços e de saberes que não apenas descrevem, como também circunscrevem cada pessoa em "seu" lugar social. O autor explica, por exemplo, que as práticas de nomeação e as histórias contadas visam estabelecer vínculos entre um sujeito e seu nome: "para que uma criança receba o 
nome, uma rede de saberes é articulada, conformandose suas ações, descrevendo-se os aspectos físicos, os gostos, as preferências, e ao ser descrita ela também vai sendo posicionada socialmente" (p. 5). Outro aspecto analisado por Catafesto de Souza (2010) é a dimensão espaço-temporal, observando, de um lado, os processos migratórios que estabelecem certos vínculos com o território Mbyá Guarani e entre as pessoas que nele habitam e, de outro lado, a marcação dos tempos na vida das crianças como estratégias de individualização e de diferenciação. As análises desenvolvidas pelo autor dão conta do caráter cultural, histórico e contingente de tais práticas, que têm uma imensa funcionalidade, mas que também são tensionadas, contestadas e alteradas no dinamismo da vida deste povo.

Sobre as identidades/diferenças indígenas, pesquisas como as de Oliveira (2001), Costa (2003), Bonin (2007), Paes (2008), Aguiar (2012) discutem certos "olhares poderosos" de cientistas, antropólogos, viajantes, pesquisadores, jornalistas, a partir dos quais se define o que é normal e o que é desviante e também se estabelece a positividade da identidade e a negatividade da diferença - narrada então por supostas carências. Outros estudos partem de uma abordagem do multiculturalismo crítico, problematizando os essencialismos, a partir dos quais a pluralidade cultural é naturalizada, tomada como um fato dado que precisaria ser mais bem compreendido para, através do conhecimento, emergir uma atitude tolerante e respeitosa (ver, por exemplo, BATISTA, 2005; CALDERONI, 2011; URQUIZA, 2013).

Oliveira (2001), Kindel (2003), Bonin (2007) e Paes (2008) mostram (a partir de estratégias analíticas e de artefatos diferentes) uma variedade de formas de representar que colaboram na fabricação de diferencialismos - ou seja, na definição de quem são os diferentes, fixando também assim quem são os "iguais". Já Aguiar (2012) focaliza a emergência de representações da diferença indígena, em alguns casos tratada como natural, a ser tolerada e respeitada, em outros como algo inoportuno e incômodo, que pode implicar risco e que, por isso, exige posicionamentos e ações oficiais para assegurar o bom governo das condutas desses sujeitos.

Sob uma perspectiva um pouco diferente, Calderoni (2011) discute as "ciladas" dos discursos modernos de igualdade, que se configuram na forma de leis, constituem os sujeitos e se disseminam na escola. Ela exemplifica com situações em que os professores não reconhecem a presença de alunos indígenas em suas salas de aula ou, quando inqueridos sobre a situação de alunos indígenas, recorrem ao discurso naturalizado, cristalizado, da igualdade, afirmando que estes são tratados "do mesmo jeito" que os demais. Na prática, contudo, o discurso da igualdade dissolve a diferença e impossibilita questionar as condições desiguais de acesso aos bens materiais e simbólicos, como também aos recursos. O paradoxo atual da escola, que até então se pautava em políticas e ações pedagógicas universais, é que ela se vê hoje interpelada pelas políticas da diferença.

\section{CONSIDERAÇõES FINAIS}

Longe de pretender ser exaustivo, este artigo buscou apontar tendências na construção do conhecimento, quando se articulam três descritores - temática indígena, Estudos Culturais e Educação. A articulação mostra-se especialmente produtiva, considerando as pesquisas aqui apresentadas. Um aspecto a salientar é a problematização da ideia abstrata de diversidade cultural - mobilizada a partir de algumas perspectivas multiculturalistas que apregoam atitudes de tolerância frente a algo tomado como natural. As pesquisas mostram que a retórica de tolerância para com a diversidade tende a ressaltar o que há de superficial e externo nas culturas, exaltando o exótico que demarca sua distância de uma suposta cultura modelar - a europeia. Por sua vez, o campo dos Estudos Culturais parece favorecer o desenvolvimento de análises críticas, que focalizam as desigualdades, as relações de poder, as práticas representacionais e as políticas em torno das identidades/diferenças. São acionados, nestes estudos, diversos conceitos e abordagens teóricas que problematizam visões eurocêntricas, repertórios depreciativos e essencialismos, mostrando que há uma tendência hegemônica de atribuir, ao "outro"/indígena, características que fazem dele um ser estranho, objeto de curiosidade, de escrutínio.

Em pesquisas que se valem de referenciais teóricos culturalistas abandona-se, conforme buscamos demonstrar neste artigo, a noção reducionista da cultura e a abordagem essencialista das identidades/diferenças. Examinam-se as condições em que estas são produzidas, moldadas, fixadas, mas também são contestadas, questionadas e disputadas, valendo-se de produções midiáticas, de narrativas cotidianas, de práticas escolares, de falas e depoimentos dos próprios indígenas. Nota-se um grande esforço intelectual para mostrar que o terreno do significado é um terreno de luta e contestação. São variados os caminhos investigativos e os referenciais que embasam as pesquisas, mas estas compartilham o compromisso de examinar as práticas representacionais como estando implicadas com relações de poder (o poder de narrar, de representar, de estabelecer parâmetros, de definir o correto sentido das coisas).

Ressalta-se, por fim, a produtividade deste tipo de abordagem teórica da temática indígena e, ainda mais, seu potencial para desacomodar, contestar, deslocar, examinar a partir de outras lentes o muito que já foi dito, 
escrito, estabelecido, prescrito sobre quem são/como são os indígenas.

\section{REFERÊNCIAS}

AGUIAR, José Vicente de Souza. Narrativas sobre povos indígenas na Amazônia. 2011. 215f. Tese (Doutorado em Educação) - Faculdade de Educação, Universidade Federal do Rio Grande do Sul, Porto Alegre, 2011.

AMARAL, Marise Basso. Histórias de viagem e a produção cultural da natureza: a paisagem do Rio Grande do Sul segundo os viajantes estrangeiros do século XIX. 2003. 339f. Tese (Doutorado em Educação) - Faculdade de Educação, Universidade Federal do Rio Grande do Sul, Porto Alegre, 2003.

BATISTA, Teresinha Aparecida da Silva. A luta por uma escola indígena em Te'yikue Caarapó/MS. 2005. 156f. Dissertação (Mestrado em Educação) - Faculdade de Educação, Universidade Católica Dom Bosco, Campo Grande, 2005.

BONIN, Iara Tatiana. Literatura infantil de autoria indígena: diálogos, mesclas, deslocamentos. Currículo sem Fronteiras, v. 12, p. 36-51, 2012.

BONIN, Iara Tatiana. $\mathbf{E}$ por falar em povos indígenas... quais narrativas contam em práticas pedagógicas? 2007. 220f. Tese (Doutorado em Educação) - Faculdade de Educação, Universidade Federal do Rio Grande do Sul, Porto Alegre, 2007.

CALDERONI, Valéria Aparecida Mendonça de Oliveira. Nas tramas da igualdade e da diferença frente à alteridade dos alunos indígenas. 2011. 225f. Dissertação (Mestrado em Educação) - Faculdade de Educação, Universidade Católica Dom Bosco, Campo Grande, 2011.

COSTA, Gilcilene Dias da. Entre a política e a poética do texto cultural: a produção das diferenças na revista Nova Escola. 2003. 136. Dissertação (Mestrado em Educação) Faculdade de Educação, Universidade Federal do Rio Grande do Sul, Porto Alegre, 2003.

COSTA, Helouise. Um olhar que aprisiona o outro: o retrato do índio e o papel do fotojornalismo na revista $\mathbf{O}$ Cruzeiro. Imagens, Campinas, Editora da UNICAMP, n. 2, ago. 1994.

HALL, Stuart. Representation, cultural representations and signifying practices. London: Thousands Oaks; New Delhi: Sage, 1997.

KINDEL, Eunice Aita Isaia. A natureza no desenho animado ensinando sobre homem, mulher, raça, etnia e outras coisas mais.... 2003. 195f. Tese (Doutorado em Educação) - Faculdade de Educação, Universidade Federal do Rio Grande do Sul, Porto Alegre, 2003.

KIRCHOF, Edgar Roberto; BONIN, Iara Tatiana. Identidades étnicas e tecnologias de informação: uma análise do site Índios Online. Ciências Humanas e Sociais em Revista, v. 32, p. 1-14, 2010.

MORONI, Rogério Batalha Rocha. Direitos indígenas e educação escolar: parâmetros da escola para a efetividade de direitos dos Kaiowá e Guarani e a concepção dos professores indígenas sobre sustentabilidade e territorialidade. 2012. $133 f$. Dissertação (Mestrado em Educação) - Faculdade de Educação, Universidade Católica Dom Bosco, Campo Grande, 2012.

PAES, Maria Helena Rodrigues. Representações cinematográficas "ensinando" sobre o índio brasileiro: selvagem e herói nas tramas do império. 2008. 154f. Tese
(Doutorado em Educação) - Faculdade de Educação, Universidade Federal do Rio Grande do Sul, Porto Alegre, 2008.

SAMPAIO, Shaula Maíra Vicentini de. "Uma floresta tocada apenas por homens puros..." Ou do que aprendemos com os discursos contemporâneos sobre a Amazônia. 2012. 296f. Tese (Doutorado em Educação) - Faculdade de Educação, Universidade Federal do Rio Grande do Sul, Porto Alegre, 2012.

SILVA, Kassius Nitske da. Jogos dos Povos Indígenas: estratégias pedagógicas, negociações e práticas representacionais. 2012. 157f. Dissertação (Mestrado em Educação) Faculdade de Educação, Universidade Luterana do Brasil, 2012.

SOUZA, Luiz Antonio Catafesto de. Crianças Mbyá-Guarani: práticas educativas \& tecnologias de produção da pessoa. 2010. 136f. Dissertação (Mestrado em Educação) - Universidade Luterana do Brasil, Canoas, 2010.

OLIVEIRA, Teresinha Silva de. Olhares Poderosos. 2001. Dissertação (Mestrado em Educação) - Faculdade de Educação, Universidade Federal do Rio Grande do Sul, Porto Alegre, 2001.

URQUIZA, Moema Guedes. Identidades indígenas na mídia: um estudo com professores indígenas sobre identidade/ diferença e representação. 2013. 82f. Dissertação (Mestrado em Educação) - Faculdade de Educação, Universidade Católica Dom Bosco, Campo Grande, 2013.

\section{NOTAS}

${ }^{1}$ Que altera o artigo 26-A da Lei de Diretrizes e Bases da Educação Nacional.

2 Disponível em: <http://www.lume.ufrgs.br>. Acesso em: 10 maio 2013.

3 Disponível em: $<$ https://memphis.ulbranet.com.br/ALEPH $>$. Acesso em: 10 maio 2013

4 Disponível em: <http://site.ucdb.br/cursos/4/mestrado-e-doutorado/32/ mestrado-e-doutorado-em-educacao/627/dissertacoes-defendidas/1144>. Acesso em: 12 maio 2013.

5 Desenvolvida junto ao PPGEDU/UFRGS sob a orientação de Rosa Maria Hessel Silveira.

${ }^{6}$ Desenvolvida junto ao PPGEDU/UFRGS sob a orientação de Rosa Maria Hessel Silveira.

7 Desenvolvida junto ao PPGEDU/UCDB sob a orientação de Adir Casaro Nascimento.

${ }^{8}$ Desenvolvida junto ao PPGEDU/UFRGS sob a orientação da professora Rosa Maria Hessel Silveira.

9 Desenvolvida junto ao PPGEDU/UFRGS sob a orientação da professora Rosa Maria Hessel Silveira.

${ }^{10}$ Desenvolvida junto ao PPGEDU/ULBRA sob a orientação da professora Iara Tatiana Bonin.

${ }^{11}$ Desenvolvida junto ao PPGEDU/ULBRA sob a orientação da professora Iara Tatiana Bonin.

${ }^{12}$ Desenvolvida junto ao PPGEDU/UCDB, orientada por Antônio Jacó Brand.

${ }^{13}$ Desenvolvida junto ao PPGEDU/UCDB, orientada por Antônio Jacó Brand.

${ }^{14}$ Desenvolvida junto ao PPGEDU/UFRGS sob a orientação de Maria Lúcia Castagna Wortmann.

${ }^{15}$ Desenvolvida junto ao PPGEDU/UFRGS sob a orientação de Maria Lúcia Castagna Wortmann.

${ }^{16}$ Desenvolvida junto ao PPGEDU/UFRGS sob a orientação de Rosa Maria Hessel Silveira.

${ }^{17}$ Desenvolvida junto ao PPGEDU/UFRGS sob a orientação de Maria Lúcia Castagna Wortmann.

${ }^{18}$ Desenvolvida junto ao PPGEDU/UCDB sob a orientação de Adir Casaro Nascimento.

Artigo recebido em setembro 2014.

Aprovado em janeiro 2015. 